\title{
Reducing the heterogeneity of xylan through
}

\section{processing}

Wei Zhang ${ }^{a, b}$, Amanda M. Johnson ${ }^{d}$, Justin R. Barone ${ }^{a, c}$, and Scott Renneckar ${ }^{b, d, *}$

${ }^{\mathrm{a}}$ Macromolecules and Interfaces Institute, Virginia Tech, Blacksburg, VA, 24061, United States

${ }^{\mathrm{b}}$ Department of Sustainable Biomaterials, Virginia Tech, Blacksburg, VA, 24061, United States

${ }^{\mathrm{c}}$ Department of Biological Science and Engineering, Virginia Tech, Blacksburg, VA, 24061,

United States

${ }^{\mathrm{d}}$ Department of Wood Science, University of British Columbia, Vancouver, BC Canada, V6T1Z4

* Corresponding author. Address: Forest Sciences Centre 4034, 2424 Main Mall, Vancouver, British Columbia V6T 1Z4, Canada. Tel.: 604-827-0637

Email address: scott.renneckar@ubc.ca

Keywords: Fractionation, Glycerol thermal processing, Glucuronoxylan, Water insoluble xylan, Molecular weight analysis, Rhamnan 
Abbreviations: GTP, glycerol thermal processing; SG, extractive-free sweet gum; WIX, crude water insoluble xylan; WSX, crude water soluble xylan; $M_{n}$, number average molecular weight; $M_{w}$, weight average molecular weight; DP, degree of polymerization; PDI, polydispersity index.

ABSTRACT Glycerol thermal processing (GTP) of hardwood biomass at temperatures between 200-240 ${ }^{\circ} \mathrm{C}$ facilitated stepwise biopolymer fractionation, while limiting significant degradation of the major hemicellulose, glucuronoxylan, into water-extractable oligosaccharides. After GTP pretreatment and sequential water and organic solvent extraction, up to $80 \%$ of the initial xylan remained in the pretreated biomass. The majority of the xylan from GTP pretreated and water/solvent extracted biomass was removed using a mild alkali extraction and the composition was compared to xylan directly isolated from untreated hardwood. The precipitated xylan from the neutralized alkaline filtrate was isolated as a water insoluble xylan portion (WIX). The residual xylan dissolved in the neutralized filtrate was precipitated in cold methanol and recovered as the water soluble xylan portion (WSX). Results showed that xylan in WIX was in a polymeric form with a number average degree of polymerization (DP) over 100 , whereas the WSX had a much lower average DP of 27 (ca) and contained more substitution. As the processing severity increased during GTP pretreatment, the proportion of WIX increased and the purity of the xylan within the WIX sample reached $84 \%$ based on compositional analysis. FT-IR analysis of WIX revealed that the xylan isolated after GTP contained peaks that related to a reduced carbonyl signal compared to the control. Furthermore, crude WSX contained less xylan with more lignin contamination at severe GTP conditions. The recovery of the xylan in two portions facilitated a preferential purification strategy resulting in WIX with an extremely narrow polydispersity index between 1.1 and 1.25 , dependent upon the GTP severity. This study 
provided insight into fractionating higher molecular weight xylan that may serve value-added applications such as healthcare and advanced packaging.

\section{Introduction}

Hemicelluloses represent a complex mixture of hetero-polysaccharides and serve as key structural components within the plant cell wall. The composition and structure of the hemicelluloses are highly dependent on the biomass species. For many hardwoods, the main hemicellulose is $O$-acetyl-4- $O$-methyl-glucuronoxylan (xylan), which comprises $15-30 \%$ of wood dry weight (Fengel \& Wegener, 1983). Xylan has a $\beta-1,4$ linked xylan backbone with acetyl groups appearing on the $\mathrm{C}_{2 / 3}$ of the xylopyranose ring ( $\sim 3.5$ acetyl/10 rings) (Glaudemans \& Timell, 1958; Sjöström, 1993). Additionally, 4-O-methyl glucuronic acid is $\alpha-1,2$ linked to the backbone as a major side-group ( 1 glucuronic acid per 10 pyranose rings) (Sjöström, 1993) making the structure slightly branched, but the branches are terminal. Compared to cellulose, the chain length of hemicellulose is reduced as the degree of polymerization (DP) of native hardwood xylan is in the range of 100 to 200 (Goring \& Timell, 1960; Husemann, 1940; Koshijima, Timell \& Zinbo, 1965; LeBel, Goring \& Timell, 1963; Mian \& Timell, 1960), but that of isolated xylan is highly dependent on the isolation method (Glasser, Kaar, Jain \& Sealey, 2000).

Hemicelluloses, especially xylans are finding new uses in industrial applications. Due to their oxygen barrier properties when included in laminate films, hardwood xylan has been proposed for use in diverse applications in food packaging materials (Gröndahl, Eriksson \& Gatenholm, 2004), as an edible film when mixed with wheat gluten (Kayserilioğlu, Bakir, Yilmaz \& Akkaş, 2003), and as a hydrogel with chitosan for biomedical applications (Gabrielii, Gatenholm, 
Glasser, Jain \& Kenne, 2000). Also, xylan derivatives, modified through etherification and esterification, have promise in applications such as drug delivery, surfactants, and antimicrobial agents (Deutschmann \& Dekker, 2012; Hansen \& Plackett, 2008; Petzold-Welcke, Schwikal, Daus \& Heinze, 2014). Hence, the utility of xylans has been demonstrated and provides a potential justification for better methods of separation and recovery, along with understanding how different isolation methods impact its structure.

Xylan isolation dates back to the late 1800's when Thomsen treated wood with alkali and subsequently precipitated "wood gum" with acidic ethanol that led the way to investigating xylan constitution by Johnson and co-workers (Allen \& Tollens, 1890). Outside of utilizing dimethylsulfoxide to extract acetylated xylan from holocellulose (Hägglund, Lindberg \& McPherson, 1956), the historic cold alkali extraction and acidic alcohol precipitation has largely been the primary method to isolate xylan from wood for more than a century. One of the most common methods for lab scale xylan isolation includes delignification to produce holocellulose through acetic acid/sodium chlorite treatment, followed by a sequential alkaline extraction of xylan using sodium hydroxide or potassium hydroxide between $4 \%$ or $24 \%$ (Glaudemans \& Timell, 1958; Mian \& Timell, 1960; Wise, Murphy \& d'Addieco, 1946). This produces an extensively deactylated, slightly branched 4-O-methylglucuronoxylan from hardwood and in certain species, like white birch, gives near theoretical yield. In contrast to this method, direct xylan isolation by alkali treatment followed by sequential bleaching using hydrogen peroxide has also been studied for xylan isolation to minimize xylan structural modification (Gabrielii, Gatenholm, Glasser, Jain \& Kenne, 2000). Glasser et al. (Glasser, Kaar, Jain \& Sealey, 2000) compared different isolation protocols for heteropolysaccharides from barley husks and yellowpoplar and found that alkali extraction was most efficient for polymeric xylan isolation. 
Furthermore, fractional recovery of xylan has been reviewed in detail (Peng, Peng, Xu \& Sun, 2012) and a recent study has shown that xylan has more precipitate formed overall in ethanol than neutralized solvent, if the recovery processes are separated (Stoklosa \& Hodge, 2012). However, most research is interested in maximizing yield and xylan is typically recovered by precipitation in acidic ethanol or graded ethanol levels as developed by LeBel and co-workers (LeBel \& Goring, 1963). There is very little information about the differences in the structure of the precipitated xylans in neutralized solvent versus ethanol, especially for xylan directly extracted from wood. Furthermore, with the growing biorefinery industry and the increase in prehydrolysis kraft pulp production for dissolving pulp, enhancing the isolation of xylan is viewed favorable to obtain a valuable source of by-product for advanced applications. With the biorefinery industry, pretreatments with alkali or some organosolv methods have been proposed to delignify the biomass, which results in isolated xylan with better purity and lower polydispersity (Glasser, Kaar, Jain \& Sealey, 2000). However, pretreatments involving acids or autocatalyzed reactions lead to severe hydrolytic degradation of hemicellulose, which are not appropriate for the isolation of polymeric xylan (Glasser \& Wright, 1998; Overend \& Chornet, 1987) and are therefore less desirable in this regard for material applications.

In this research, glycerol thermal processing (GTP) involving shearing of biomass at elevated temperatures between $200-240{ }^{\circ} \mathrm{C}$ in the presence of anhydrous glycerol was utilized as a pretreatment method for polymeric xylan isolation from the hardwood, Liquidambar styraciflua, known as sweet gum. Previous research (Zhang, Barone \& Renneckar, 2015) demonstrated that the GTP pretreatment disrupted the biomass cell wall structure by extensively removing hemicelluloses side groups potentially involved in lignin-carbohydrate linkages, while also enhancing specific surface area of the cell wall and enzymatic hydrolysis of cellulose (Zhang, 
Sathitsuksanoh, Barone \& Renneckar, 2016). As a result, lignin became extractable from the GTP treated biomass via mild solvent extraction with aqueous dioxane (Zhang, Sathitsuksanoh, Simmons, Frazier, Barone \& Renneckar, 2016), while more than $80 \%$ of the xylan was preserved in the fiber. With the potential applications for polymeric xylan discussed above, xylan extracted from untreated biomass and GTP pretreated biomass after mild delignification was studied to determine processing and recovery on composition and structure. The isolated xylan was analyzed for yield, purity, and molecular weight, and its structural properties were further correlated to GTP pretreatment conditions. As the GTP processing conditions surpass the usually reported thermal stability of xylan, the work reveals a novel xylan isolation route with detailed characterization for this important by-product of the developing biorefinery industry.

\section{Experimental}

Chemicals and reagents used in this research were purchased from Sigma-Aldrich, Alfa Aesar and MP Biomedicals, and used as received. Deionized water (DI-water, $18.2 \mathrm{~m} \Omega$ ) was used in all cases. Extractive-free sweet gum (Liquidambar styracuflua) fiber was used as previously reported (Zhang, Barone \& Renneckar, 2015).

\subsection{Glycerol thermal processing (GTP) pretreatment}

Sweet gum, milled to a particle size less than $420 \mathrm{~mm}$ (40 mesh) but greater than $250 \mathrm{~mm}(60$ mesh) was pretreated on a melt compounder with high shear rollers in the presence of glycerol

(Zhang, Barone \& Renneckar, 2015). The GTP pretreatment severity parameter $\left(R_{0}\right)$ was calculated according to an equation developed by Overend and Chornet (Overend \& Chornet, 1987) with temperature and residence times in the range of $200-240{ }^{\circ} \mathrm{C}$ and 4 to $12 \mathrm{~min}$, respectively: . 
Equation $1 \quad R_{0}=\mathrm{t} * \mathrm{e}^{(\mathrm{T}-100) / 14.75}$ where $\mathrm{t}$ is the time and $\mathrm{T}$ is the temperature of the preheated compounder.

After pretreatment, the GTP pretreated biomass was collected from the mixing head and stored at $4{ }^{\circ} \mathrm{C}$ until further analysis. Samples for each severity condition were run in triplicate.

\subsection{Water extraction and delignification}

The GTP pretreated biomass was firstly extracted by water to remove the glycerol residue and any degraded components. After water extraction, the GTP biomass was freeze-dried followed by vacuum-drying and a mild solvent extraction with aqueous dioxane was then performed to isolate lignin from the GTP pretreated biomass. The solvent extracted GTP biomass was thoroughly washed by deionized water before drying. Details for these procedures are outlined elsewhere (Zhang, Barone \& Renneckar, 2015).

\subsection{Alkali extraction.}

Milled sweet gum (control) and solvent extracted GTP sweetgum were alkali extracted to isolate xylan. The dried biomass was extracted at ambient temperature for 24 hours with continuous stirring using a $1 \mathrm{M}$ sodium hydroxide solution at a ratio of $2.5 / 100(\mathrm{~g} / \mathrm{ml})$ under nitrogen. After the extraction, the alkaline mixture was centrifuged to separate solid residues and the alkali extract. Sequentially $100 \mathrm{ml} 1 \mathrm{M}$ sodium hydroxide solution and $100 \mathrm{ml}$ deionized water was used to wash the solid residue, and the washing liquids were collected and combined with the alkaline extract. The solid residue was thoroughly washed using DI water until the pH was neutral and the material was then freeze-dried followed by vacuum drying for mass balance analysis.

The combined alkaline extract and washing solution was neutralized to $\mathrm{pH}=6.0$ with acetic acid for water-insoluble and water-soluble xylan (WIX and WSX, respectively). Detailed procedures 
are provided in Fig. 1. Generally, the precipitates formed during neutralization were collected through centrifugation and the supernatant was collected separately. The precipitates were then re-dispersed in methanol for purification and collected as water-insoluble xylan (WIX). The supernatant collected above was evaporated to less than $100 \mathrm{ml}$ under reduced pressure and in the presence of antifoam 204 (a mixture of organic non-silicone polypropylene based polyether dispersions, Sigma-Aldrich), and then was added drop-wise into $400 \mathrm{ml}$ methanol with vigorous stirring. The precipitates formed during this process were also collected through centrifugation and are referred to as water-soluble xylan (WSX). The WIX and WSX were vacuum dried thoroughly for further analysis.

Fig. 1. Alkali extraction schematic to recover the crude water-insoluble and water-soluble xylan.

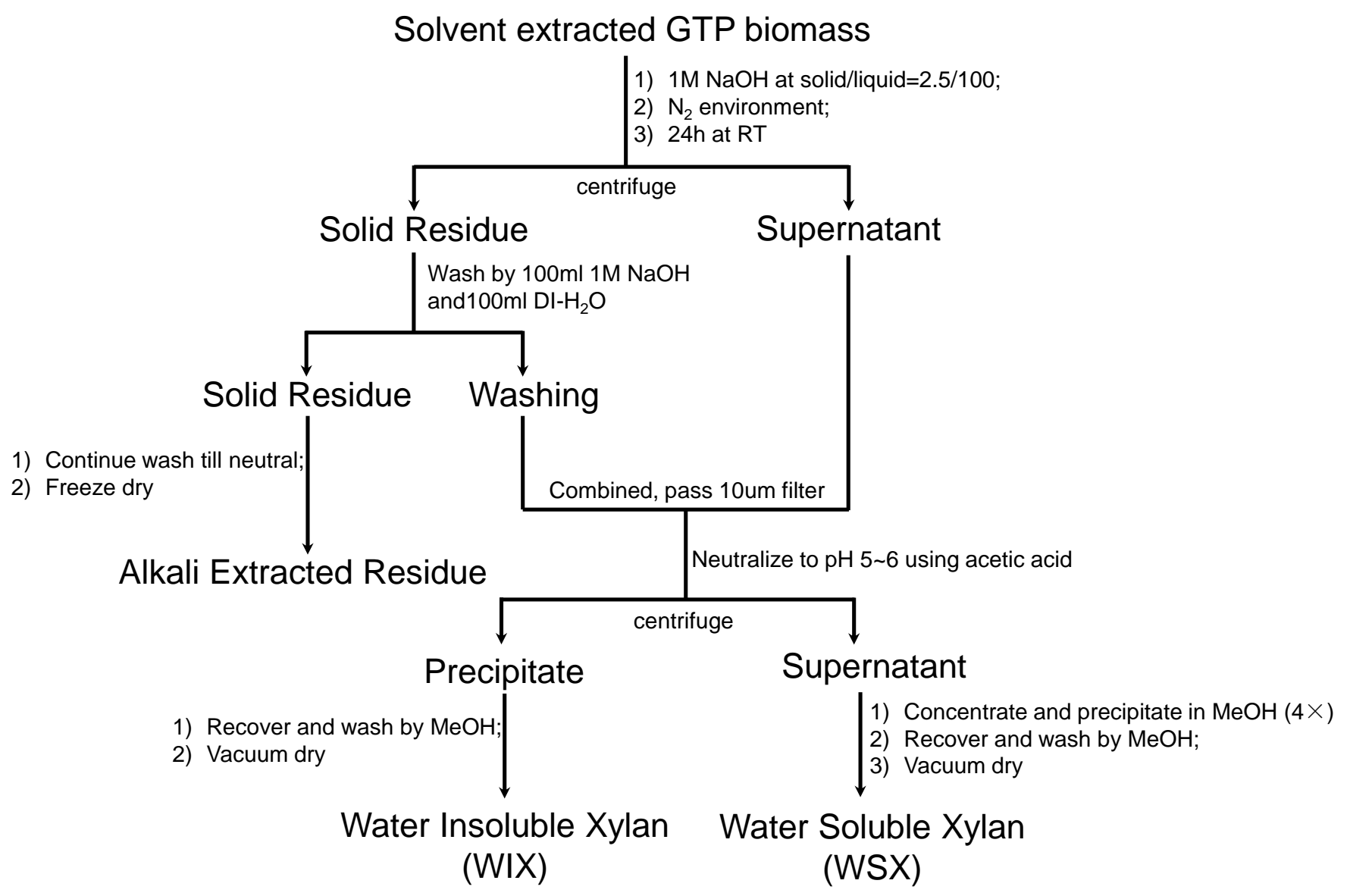




\subsection{Compositional and purity analysis}

The structural carbohydrates and Klason lignin in GTP biomass before and after alkaline extraction were analyzed according to the NREL laboratory analytical procedure (LAP) (Sluiter et al., 2008) in duplicate (Zhang, Barone \& Renneckar, 2015).

A two-step acid hydrolysis with slight modification of reduced starting mass was used for WIX purity analysis. Generally, $100 \mathrm{mg}$ of thoroughly dried WIX was first hydrolyzed using $1 \mathrm{ml}$ $72 \%$ sulfuric acid at $30{ }^{\circ} \mathrm{C}$ with continuous stirring for 1 hour. A $4 \%$ acid hydrolysis was then conducted for 1 hour at $121{ }^{\circ} \mathrm{C}$ in an autoclave before filtration. The filtrate containing hydrolyzed monosaccharides was then analyzed quantitatively using ion chromatography (Zhang, Barone \& Renneckar, 2015). The Klason lignin left in the crucible was dried in a muffle furnace at $105{ }^{\circ} \mathrm{C}$ for 12 hours then burned at $575{ }^{\circ} \mathrm{C}$ for 24 hours. The mass before and after the $575{ }^{\circ} \mathrm{C}$ combustion was recorded for Klason lignin calculation.

A purity analysis of WSX isolated from non-pretreated sweet gum was conducted using the same method as above for WIX, using $50 \mathrm{mg}$ WSX and $500 \mu \mathrm{l} 72 \%$ sulfuric acid. The WSX isolated from the pre-delignified GTP biomass was not analyzed for purity due to the limited yield.

The uronic acid content of the control xylans from the unpretreated sweet gum was determined using an enzymatic kit (Megazyme, Ireland). WSX and WIX were ground using a mortar and pestle. These samples were added to $1.3 \mathrm{M} \mathrm{HCl}$ in a Pyrex® round-bottomed flask at a solids loading of $4 \%$. The mixture was hydrolyzed at $100^{\circ} \mathrm{C}$ for 1 hour with constant stirring. The hydrolysate was neutralized with an equal volume of $1.3 \mathrm{M} \mathrm{NaOH}$, then water was added to a final solids loading of $0.4 \%$. Uronic acid in the hydrolysate was measured as per the kit instructions. Uronate dehydrogenase, which oxidizes uronic acids, is added to the hydrolysate in 
the presence of nicotinamide-adenine dinucleotide $\left(\mathrm{NAD}^{+}\right)$. The amount of glucuronic acid oxidized is stoichiometric to nicotinamide-adenine dinucleotide (NADH) formed. This is monitored by an increase in absorbance at $340 \mathrm{~nm}\left(\varepsilon=6300 \mathrm{~L} \cdot \mathrm{mol}^{-1} \cdot \mathrm{cm}^{-1}\right)$. Note, hydrolysis impacts detection of the glucuronic acid as noted in the standard compared to the hydrolyzed standard. A correction factor was determined for the difference in detected glucuronic acid and used for the reported values.

\subsection{Fourier transform infrared spectroscopy (FT-IR) of WIX and WSX}

FT-IR spectra of WIX and WSX were collected in transmission mode on a Thermal Nicolet 8700 spectrometer. About $5 \mathrm{mg}$ of thoroughly dried WIX or WSX was mixed with $100 \mathrm{mg} \mathrm{KBr}$ to make transparent pellets. A total of 256 scans was collected per sample with a resolution of $4 \mathrm{~cm}^{-}$

1 in the range of $4000-500 \mathrm{~cm}^{-1}$. The spectra were manually baseline corrected using a polynomial function in Omnic software. WIX and WSX spectra were further normalized to the absorbance intensity at $1085 \mathrm{~cm}^{-1}$.

\subsection{WIX carbanilation and molecular weight analysis}

Carbanilation of WIX was conducted to improve xylan solubility for molecular weight analysis. Detailed procedures for xylan carbanilation were adapted from Evans et al.(Evans, Wearne \& Wallis, 1989) with $50 \mathrm{mg}$ completely dried WIX reacted with $1 \mathrm{ml}$ phenylisocyanate in $10 \mathrm{ml}$ anhydrous DMSO. Dry nitrogen was used to flush the reaction vial to prevent side-reactions by moisture and the reactions were carried out in a $70{ }^{\circ} \mathrm{C}$ oil bath with continuous stirring. WIX was observed to fully dissolve in the reagent in 1 hour, but the reaction was continued for 5 hours to assure full substitution. After 5 hours, $1 \mathrm{ml}$ of dry methanol was added to consume any excess phenylisocyanate. The reaction mixture was then cooled in an ice-water bath for 5 minutes and 
the WIX carbanilates were precipitated dropwise into $100 \mathrm{ml} \mathrm{70 \%} \mathrm{(v \% )} \mathrm{methanol,} \mathrm{resulting} \mathrm{in} \mathrm{a}$ colloidal dispersion. Two drops of saturated aqueous sodium sulfate were added into the colloidal mixture with vigorous stirring to break the colloidal dispersion and precipitate the WIX carbanilates. The derivatives were then collected by centrifugation, washed with aqueous methanol and DI water, and freeze-dried. A typical reaction for xylan carbanilaton is shown in Fig. 2. The fully substituted WIX carbanilates were verified through FT-IR and ${ }^{1} \mathrm{H}-\mathrm{NMR}$.

Fig. 2. Xylan carbanilation reaction.

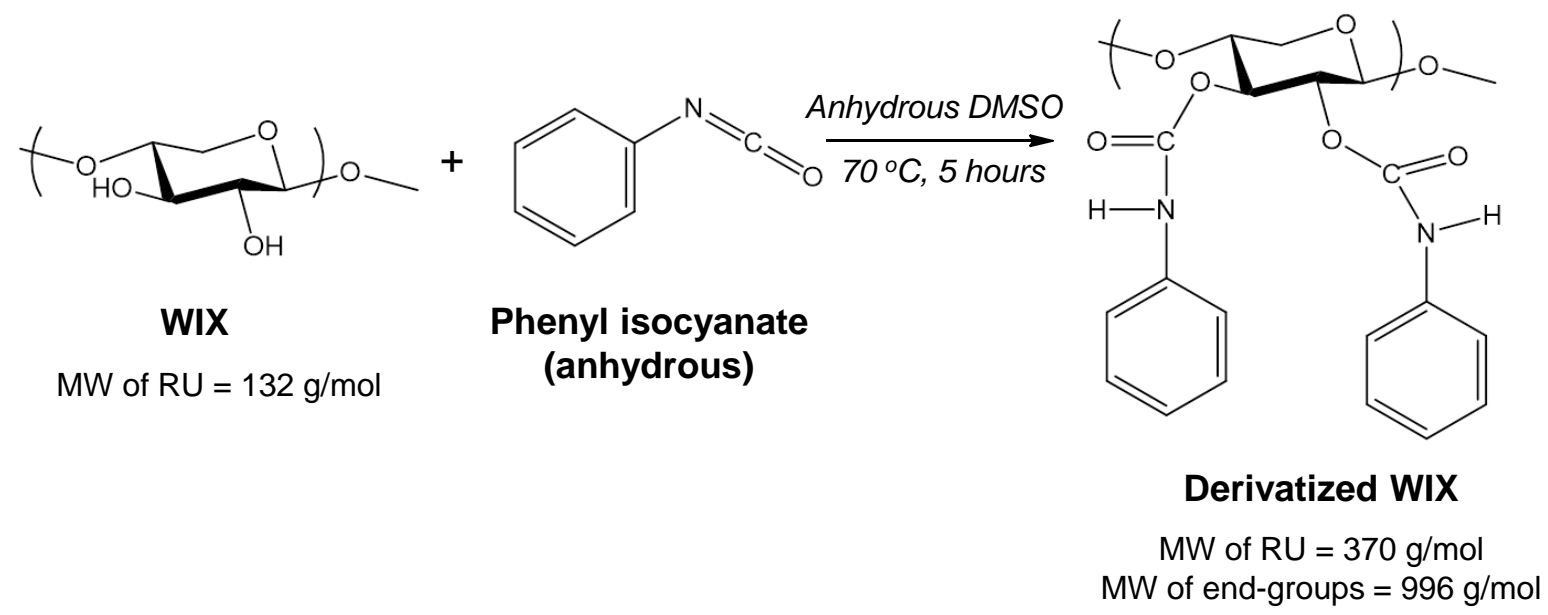

The absolute molecular weight of thoroughly dried WIX carbanilates was obtained using an Agilent 1260 Infinity Multi-Detector SEC, installed with 3 PLgel $10 \mu \mathrm{m}$ mixed-B $300 \times 7.5$ mm columns in series. N-methyl-2-pyrrolidone with $0.05 \mathrm{M} \mathrm{LiBr}$ was used as the mobile phase at 50 ${ }^{\circ} \mathrm{C}$.

\section{Results}

\subsection{Characterization of crude xylan extracted from non-treated fiber}

The alkaline extraction of 4-O-methylglucuronic acid substituted xylan from hardwood has been widely reported (Gabrielii, Gatenholm, Glasser, Jain \& Kenne, 2000; Mian \& Timell, 1960) in the literature and it has been proposed that hardwood xylan isolated through alkaline extraction 
at ambient temperature is quite similar to native xylan except for deacetylation of the backbone (Timell, 1967). However, several studies described below do not differentiate the impact that recovery through precipitation has on the xylan structure as the studies usually combine the two fractions (Gabrielii, Gatenholm, Glasser, Jain \& Kenne, 2000) or just use acidic aqueous alcohol to recover xylan. In the current study two portions of xylan were separated upon recovery during neutralization of the alkaline extract. Using this method, the water insoluble xylan (WIX) precipitated when the alkali extract was neutralized and was recovered by filtration, and the remaining water soluble xylan (WSX) in the filtrate was isolated by precipitation with methanol. For control samples, an alkali extraction was performed on non-pretreated sweet gum with a particle size between 40 and 60 mesh to yield WIX and WSX samples. This direct alkali extraction of non-pretreated biomass was effective to remove crude xylan in good yield. WIX was the major product with a recovery yield of $11.4 \% \mathrm{w} / \mathrm{w}$ of total biomass, whereas the yield of crude WSX was $5.6 \% \mathrm{w} / \mathrm{w}$ of the total biomass. As a reference, total xylan content was approximately $21 \% \mathrm{w} / \mathrm{w}$ for the extractive free biomass.

Compositional analysis of the hydrolyzed polysaccharides was performed using ion chromatography (IC) of the isolated crude xylan (Table 1) with the Klason lignin content determined gravimetrically. As shown in Table 1, the major component in both crude WIX and WSX isolated from non-treated fibers was xylan. The WIX from non-pretreated biomass had a higher xylan purity of $77 \%$, while only $55 \%$ of the WSX material recovered contained a xylan backbone. Additionally, WSX had more lignin contamination than WIX. Approximately $20 \%$ to $30 \%$ total mass was not accounted for in WIX and WSX compositional analysis (Table 1), respectively, which in part was related to glucuronic acid branches that were not detected with the ion chromatography equipment but are shown below in the FTIR analysis. However, further 
analysis of the WSX and WIX showed a glucuronic acid content of $4.3 \pm 0.9 \%$ and $5.1 \pm 1.0 \%$, respectively. These values are approximations, as the acid hydrolysis used to remove glucuronic acid groups from WSX and WIX resulted in some destruction of glucuronic acid groups. Values for the glucuronic acid content of sweetgum xylans are lower than reported in previous studies (Hurlbert \& Preston, 2001) (Torget, Walter, Himmel \& Grohmann, 1991).

Table 1 Composition of water insoluble xylan, WIX, and water soluble xylan, WSX, isolated from ground sweet gum extracted with $1.0 \mathrm{M} \mathrm{NaOH}$.

\begin{tabular}{lllllll}
\hline Sample ID & xylose $\%$ & lignin $^{1}$ & rhamnose ${ }^{2}$ & glucose $\%$ & arabinose\% & mannose\% \\
\hline \multirow{2}{*}{ WIX SGC } & 76.69 & 4.64 & 0.68 & 0.18 & 0.012 & 0.00 \\
& $(0.06)$ & $(0.83)$ & $(0.00)$ & $(0.01)$ & $(0.006)$ & $(0.00)$ \\
& 54.59 & 9.65 & 2.31 & 0.98 & 0.805 & 1.20 \\
WSX SGC & $(0.31)$ & $(1.29)$ & $(0.01)$ & $(0.01)$ & $(0.007)$ & $(0.00)$
\end{tabular}

\footnotetext{
'lignin includes acid soluble and acid insoluble lignin based on compositional analysis; ${ }^{2}$ rhamnan content contains trace amounts of galactan.
}

Compositional differences between the two xylans appear in the FTIR fingerprint region between 1800 to $600 \mathrm{~cm}^{-1}$ (Fig. 3) (Kacurakova, Capek, Sasinkova, Wellner \& Ebringerova, 2000). Analysis of the spectra revealed that WIX contained a clear carbonyl shoulder at $1720 \mathrm{~cm}^{-1}$. This shoulder was attributed to the carbonyl group of the glucuronic acid of xylan, and not acetyl groups, due to the extensive deacetylation that occurred during alkali extraction (Gabrielii, Gatenholm, Glasser, Jain \& Kenne, 2000). Further analysis of the ${ }^{1} \mathrm{H}$ spectra for the carbanilated derivatives did not reveal any glucuronic acid side groups (spectra can be found in Supporting Information Fig. S1), however, the carboxylic acids may have been partially deprotonated during 
the recovery as the $\mathrm{pH}$ of the wash was not controlled. It is known that glucuronic acid in native xylan has an average molar ratio of 1 to 10 to the xylan units (Sjöström, 1993), and this would be equivalent to about $11 \%(\mathrm{w} / \mathrm{w} \%)$ of the mass of WIX. For sweet gum, another report indicates a 1 and 6 substitution of the xylan with glucoronic acid. Both of these numbers are greater than the values determined with the enzyme kit. Other portions of the spectra indicate similarities for the common polysaccharide absorbances. In particular, the band at $1161 \mathrm{~cm}^{-1}$ is assigned to antisymmetric C-O-C stretches of glycosidic linkages. The band around $1085 \mathrm{~cm}^{-1}$ is assigned to ring C-O-C stretching and the band at $1040 \mathrm{~cm}^{-1}$ is assigned to the $\mathrm{C}-\mathrm{OH}$ stretch of primary alcohols (Lambert, Shurvell, Lightner \& Cooks, 1998; Maréchal \& Chanzy, 2000). The small band at $897 \mathrm{~cm}^{-1}$ represents the C-1 group absorbance (Kacurakova, Capek, Sasinkova, Wellner \& Ebringerova, 2000).

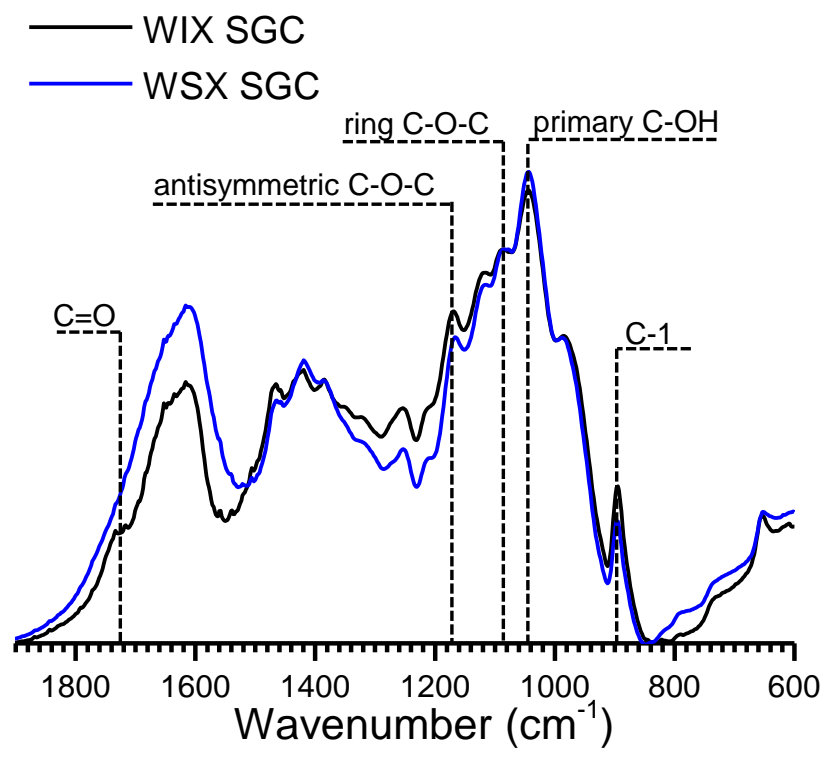

Fig. 3. FTIR comparison of WIX and WSX isolated from non-pretreated sweet gum (spectra were normalized at $1085 \mathrm{~cm}^{-1}$ ).

Based on the compositional analysis data, the molar ratios of lignin $\mathrm{C}_{9}$ units, as well as rhamnan units, for the two different crude xylans were compared relative to the xylan backbone content (Table 2). For WIX, approximately 4 lignin $\mathrm{C}_{9}$ units on average were associated with 100 xylose 
units. For WSX, the xylan was more heavily decorated with lignin, showing that each 100 xylose units have more than 10 units of lignin associated with them. Furthermore, one anhydrorhamnose ring previously has been reported to be located near the reducing end of each xylan chain after alkaline extraction of hardwood or other plants (Brown et al., 2007; Johansson \& Samuelson, 1977; Peña et al., 2007). Using the weight percentage of xylan to that of rhamnan (Table 1) and their repeat unit molecular weights, the degree of polymerization (DP) of xylan was calculated for WIX and WSX, shown in Table 2. Based on the xylan/rhamnose content, WIX had a DP of 125, corresponding with prior DP values reported for hardwood xylan (Johansson \& Samuelson, 1977). The calculated DP was further confirmed by the number average DP from GPC analysis of the carbanalized derivative, which was 127. For WSX, the corresponding chain length based on the end group calculation was 27 , suggesting a much lower molecular weight crude xylan product.

Table 2 Number of lignin $C_{9}$ units and rhamnan per 100 anhydro xylose ring and calculated DP.

\begin{tabular}{llll}
\hline Sample ID & lignin $_{\mathrm{C}_{9}}$ units & anhydro rhamnose ring $^{1}$ & DP of xylan chain $^{2}$ \\
\hline WIX SGC & 3.8 & 0.8 & 125 \\
WSX SGC & 11.1 & 3.8 & 27
\end{tabular}

${ }^{1}$ The molecular weight of lignin $\mathrm{C}_{9}$ was assumed to be $210 \mathrm{~g} / \mathrm{mol}$ (Zhang, Sathitsuksanoh, Simmons, Frazier, Barone \& Renneckar, 2016); The DP of WIX was confirmed with GPC.

Crude WIX isolated from non-treated fibers was primarily composed of xylan. The WIX portion had a higher xylan purity with less lignin contamination relative to the WSX, which the latter also had qualitative evidence (FTIR) of glucuronic acids side-groups relative to the xylan, although overall the glucuronic acid contents were similar. In contrast to WIX, the WSX had 
lower xylan purity with more lignin co-precipitated and or attached to the polysaccharide. We hypothesize that the fractional precipitation of the two components was due to the WSX low degree of polymerization and higher amount of side-chain substitutions.

\subsection{Crude xylan recovery yield from GTP treated biomass}

Glycerol thermal processing was conducted on the sweet gum fibers followed by sequential washing (water extraction) and delignification (solvent extraction). During these steps, the fate of total initial xylan was also tracked as shown in Fig. 4. Prior to xylan isolation and before the alkali extraction protocol, $75-90 \%$ of the initial xylan was preserved in the delignified GTP fibers. With increasing GTP processing severity, more xylan was lost prior to the alkali extraction (Fig. 4) as seen in the increase in percentage loss during water extraction. GTP caused increased surface area, reduction in side chains, and increased fibrillation of the cell walls of the biomass enabling extraction of these polysaccharides (Zhang, Sathitsuksanoh, Barone \& Renneckar, 2016).

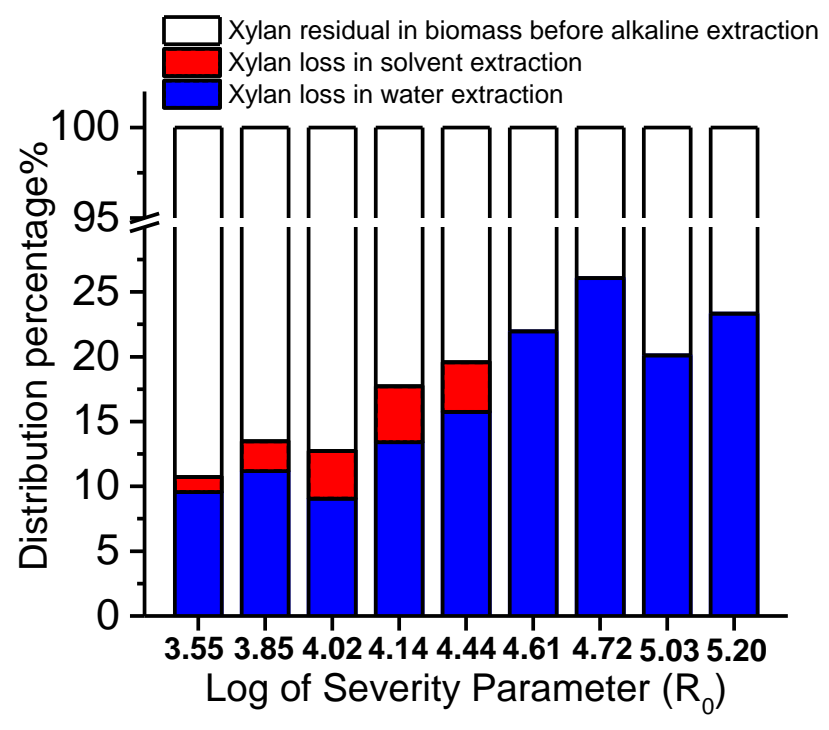

Fig. 4. Xylan distribution percentage (w/w) in sweet gum particles after GTP pretreatment, water and solvent extraction (results are calculated through average of duplicates with a $\mathrm{COV}<5 \%$ ). 
A mild alkaline extraction using $1 \%$ sodium hydroxide at ambient temperature was conducted to isolate both WIX and WSX xylan from the delignified GTP fibers. The yield of crude xylan was then calculated as the mass of recovered WIX and WSX over the total mass of delignified fibers for alkaline extraction (Fig. 5). With increasing GTP processing severity, the recovery yield of crude WIX increased, while that of the crude WSX decreased. Considering a "pre-extraction" of WSX was essentially achieved by the water extraction after GTP pretreatment, the water soluble fraction was reduced at this recovery point. Fig. 4 indicated that more xylan was lost during water extraction at high GTP severities, which suggested there was less low molecular weight and water soluble xylan present in the GTP and pre-water/solvent extracted biomass. The hemicellulose side chains usually associated with lignin-carbohydrate complex (LCC) bonds were removed during pretreatment (Zhang, Barone \& Renneckar, 2015), which would enhance the dissolution of low molecular weight xylan in the pretreated biomass. Thus, WIX became the major product from alkali extraction at the four highest severities.

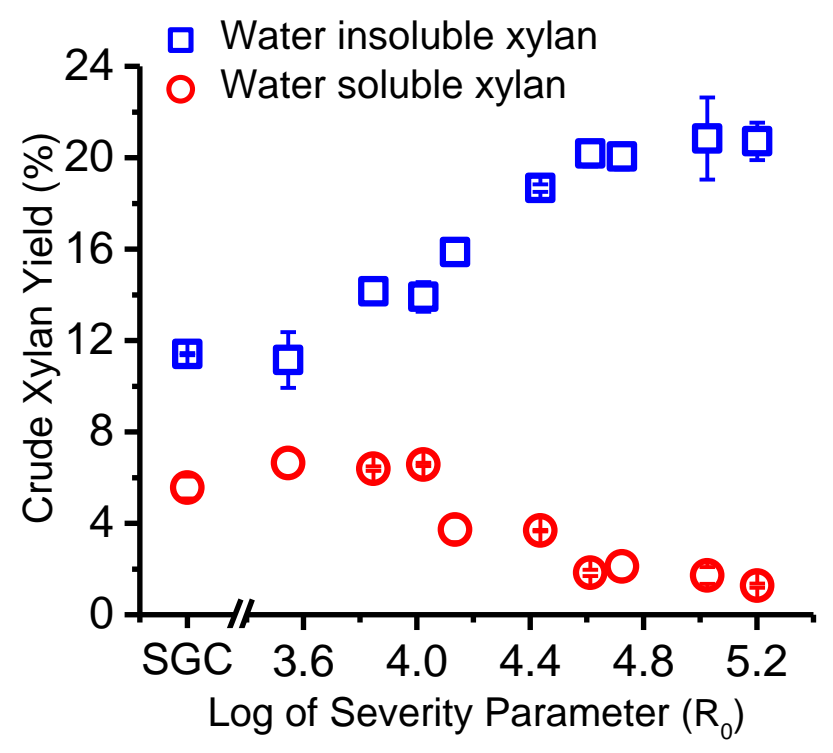

Fig. 5. Crude xylan yield based on the total biomass weight for alkali extraction.

\subsection{Purity of recovered WIX}


Compositional analysis was performed on crude WIX as a function of severity parameter (Table 3). After low severity GTP treatment of biomass, the absolute xylan content in the crude WIX was slightly lower than that of WIX isolated from non-pretreated particles. The xylan purity increased up to $84 \%$ in WIX at high GTP severities. Also, all of the isolated WIX from GTP biomass was observed to have more lignin but less rhamnan content compared to the WIX from non-pretreated particles. Overall the constitution of the crude xylan was significantly impacted by the GTP processing, as the compositional analysis totaled over $95 \% \mathrm{wt} / \mathrm{wt}$ for the highest severity parameters leaving little residual mass unaccounted for in the analysis. .

Table 3 Composition of crude WIX isolated from non-pretreated sweet gum, GTP pretreated and delignified fibers, standard deviation shown in parentheses).

\begin{tabular}{|c|c|c|c|c|c|}
\hline Sample ID & $\log \left(R_{0}\right)$ & xylose \% & $\operatorname{lignin} \%^{1}$ & rhamnose $\%^{2}$ glucose $\%$ mannose $\%$ & arabinose $\%$ \\
\hline WIX SGC & - & $76.7(0.1)$ & $4.64(0.83)$ & 3) $0.682(0.004) 0.181(0.005) 0.000(0.000)$ & $0.012(0.006)$ \\
\hline WIX 1 & 3.55 & $75.9(0.4)$ & $9.73(0.94)$ & 4) $0.589(0.010) 0.166(0.009) 0.031(0.001)$ & $0.019(0.001)$ \\
\hline WIX 2 & 3.85 & $73.3(0.1)$ & $9.83(0.34)$ & 4) $0.534(0.009) 0.123(0.003) 0.038(0.001)$ & $0.018(0.002)$ \\
\hline WIX 3 & 4.02 & $75.4(0.1)$ & $11.1(0.5)$ & $0.518(0.003) 0.108(0.003) 0.037(0.003)$ & $0.017(0.001)$ \\
\hline WIX 4 & 4.14 & $73.6(0.1)$ & $12.6(0.3)$ & $0.499(0.010) 0.124(0.002) 0.060(0.002)$ & $0.024(0.002)$ \\
\hline WIX 5 & 4.44 & $75.9(0.2)$ & $13.0(1.1)$ & $0.476(0.008) 0.148(0.007) 0.069(0.003)$ & $0.028(0.003)$ \\
\hline WIX 6 & 4.61 & $78.7(0.3)$ & $10.9(0.2)$ & $0.479(0.009) 0.134(0.000) 0.062(0.001)$ & $0.022(0.003)$ \\
\hline WIX 7 & 4.72 & $77.1(0.1)$ & $13.9(0.3)$ & $0.349(0.003) 0.241(0.007) 0.12(0.02)$ & $0.045(0.004)$ \\
\hline WIX 8 & 5.03 & $82.1(0.4)$ & $12.1(0.4)$ & $0.392(0.005) 0.277(0.032) 0.11(0.01)$ & $0.053(0.010)$ \\
\hline WIX 9 & 5.20 & $83.6(0.7)$ & $11.2(0.1)$ & $0.355(0.007) 0.292(0.006) 0.13(0.01)$ & $0.057(0.013)$ \\
\hline
\end{tabular}


units per 100 xylose rings in WIX from untreated particles, the WIX isolated from GTP treated biomass contained approximately an average of ten lignin $\mathrm{C}_{9}$ units per 100 xylose units. The relative lignin content was independent of the GTP treatment severity. This relatively higher lignin ratio is probably due to significant modification of the lignin after GTP pretreatment (Zhang, 2015). More lignin monomers (bound by weak intermolecular forces) were co-extracted with xylan during alkaline extraction. An alternative explanation could be the degraded lignin is chemically attached to the xylan during the GTP pretreatment. Extensive alkyl aryl ether bond breakage occurred on lignin (Zhang, 2015), which may have facilitated the formation of lignin xylan complexes from lignin monomers released by the GTP treatment. This result also indicated that further bleaching/purification of isolated WIX would be necessary if higher xylan purity is required in commercial processing (Glasser, Kaar, Jain \& Sealey, 2000). However, no attempt was made to purify the crude xylan via repeated precipitating with Fehling's solution and redissolving in fresh alkali, which would remove the lignin components.

For native hardwood xylan, one rhamnan ring normally is found near the end group of xylan chains (Johansson \& Samuelson, 1977), which was also confirmed in the WIX xylan isolated from the non-pretreated biomass. However, the relative content of rhamnan was inversely correlated with the GTP severity. A maximum of 50\% reduction in the amount of rhamnan was observed as GTP severity increased, indicating that rhamnan units (chain ends) may have been cleaved during GTP pretreatment (Table 4). 
Table 4 Number of lignin $\mathrm{C}_{9}$ units and rhamnan per 100 anhydro xylose ring for WIX isolated from non-pretreated and GTP pretreated sweet gum fibers.

\begin{tabular}{llcl}
\hline Sample ID & $\log \left(R_{0}\right)$ & ${\text { lignin C9 } \text { units }^{1}}$ & anhydro rhamnan ring \\
\hline WIX SGC & 0.00 & 3.8 & 0.80 \\
WIX 1 & 3.55 & 8.1 & 0.70 \\
WIX 2 & 3.85 & 8.4 & 0.66 \\
WIX 3 & 4.02 & 9.2 & 0.62 \\
WIX 4 & 4.14 & 11 & 0.61 \\
WIX 5 & 4.44 & 11 & 0.57 \\
WIX 6 & 4.61 & 8.7 & 0.55 \\
WIX 7 & 4.72 & 11 & 0.41 \\
WIX 8 & 5.03 & 9.2 & 0.43 \\
WIX 9 & 5.20 & 8.4 & 0.38
\end{tabular}

${ }^{1}$ The molecular weight of lignin C9 was assumed to be $210 \mathrm{~g} / \mathrm{mol}$ (Zhang, 2015). Sample ID can be referenced to severity parameter in Table 3.

Based on the overall biomass mass balance (Zhang, Barone \& Renneckar, 2015) and xylan purity in WIX after GTP pretreatment, a detailed mass distribution of total xylan in the initial biomass was determined (Fig. 6). This analysis indicated that very little xylan actually was recovered in the WSX form at higher GTP severities. The results indicated that approximately $19-24 \%$ of the starting xylan was removed during the subsequent water extraction after GTP at the four most 
severe conditions. In these cases, only about $1-2 \%$ more xylan was then further isolated during alkaline extraction as the WSX portion. For these severity conditions, a uniform maximum amount of alkali extractable xylan was obtained (51-57\% of total starting xylan).

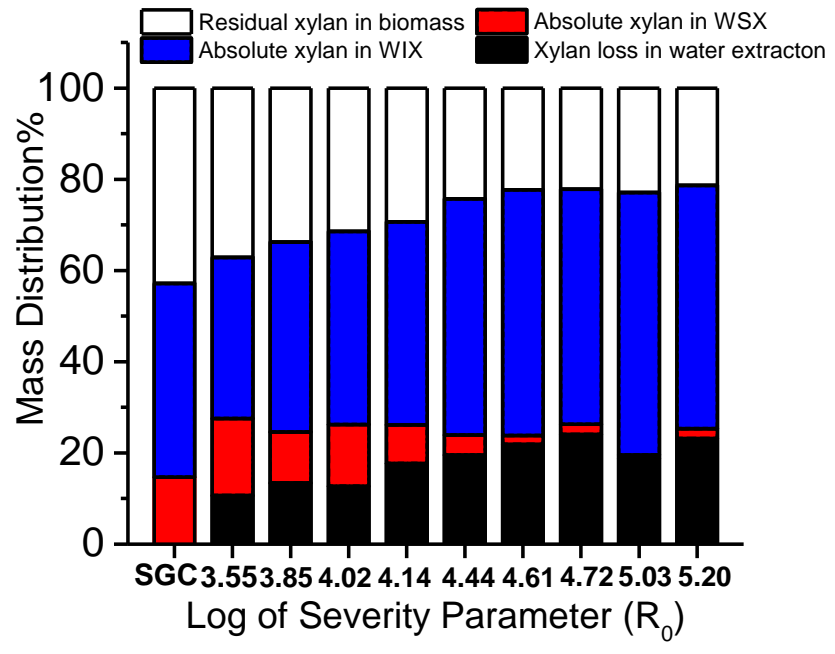

Fig. 6. Overall xylan mass distribution based on total xylan in starting biomass for nonpretreated and GTP pretreated sweet gum fibers (Results are calculated through an average of duplicates with a COV < 5\%; total xylan in original fiber is $20.6 \%$; SGC refers to the absolute xylan isolated from non-treated fibers through alkaline extraction).

\subsection{Crude WIX and WSX FTIR analysis as a function of GTP severity}

The FT-IR spectra fingerprint region for crude WIX isolated from GTP pretreated fibers (Fig. 7a) showed that the primary change in the material occurred in the resonance band at $1720 \mathrm{~cm}^{-1}$, which was assigned to the carbonyl groups of glucuronic acid in xylan (deacetylation was confirmed by the ${ }^{1}$ H-NMR in Supporting Information Fig. S1). This band existed as a shoulder in the WIX isolated from non-treated fibers, and its relative intensity to the xylan C-O-C stretching decreased with increased GTP severity. For WIX isolated from GTP fibers at high pretreatment severities, the carbonyl resonance disappeared (Fig. 7a). This result suggested that acid bearing moieties, such as glucuronic acid, were cleaved from the xylan backbone as GTP severity increased. At the highest severity GTP pretreatment, no carbonyls that would be 
associated with the glucuronic acid side groups were observed for the isolated xylan. Additionally, the spectra showed similar characteristic bands in the range of $1100-900 \mathrm{~cm}^{-1}$ for xylan independent of GTP severity. Noteworthy was the gradual change in the $1700-1600 \mathrm{~cm}^{-1}$ region, which is associated with the conjugated carbonyls of the lignin propyl chain and the aromatic skeleton, indicating that associated lignin structural changes are also occurring with increasing GTP severity.

a)

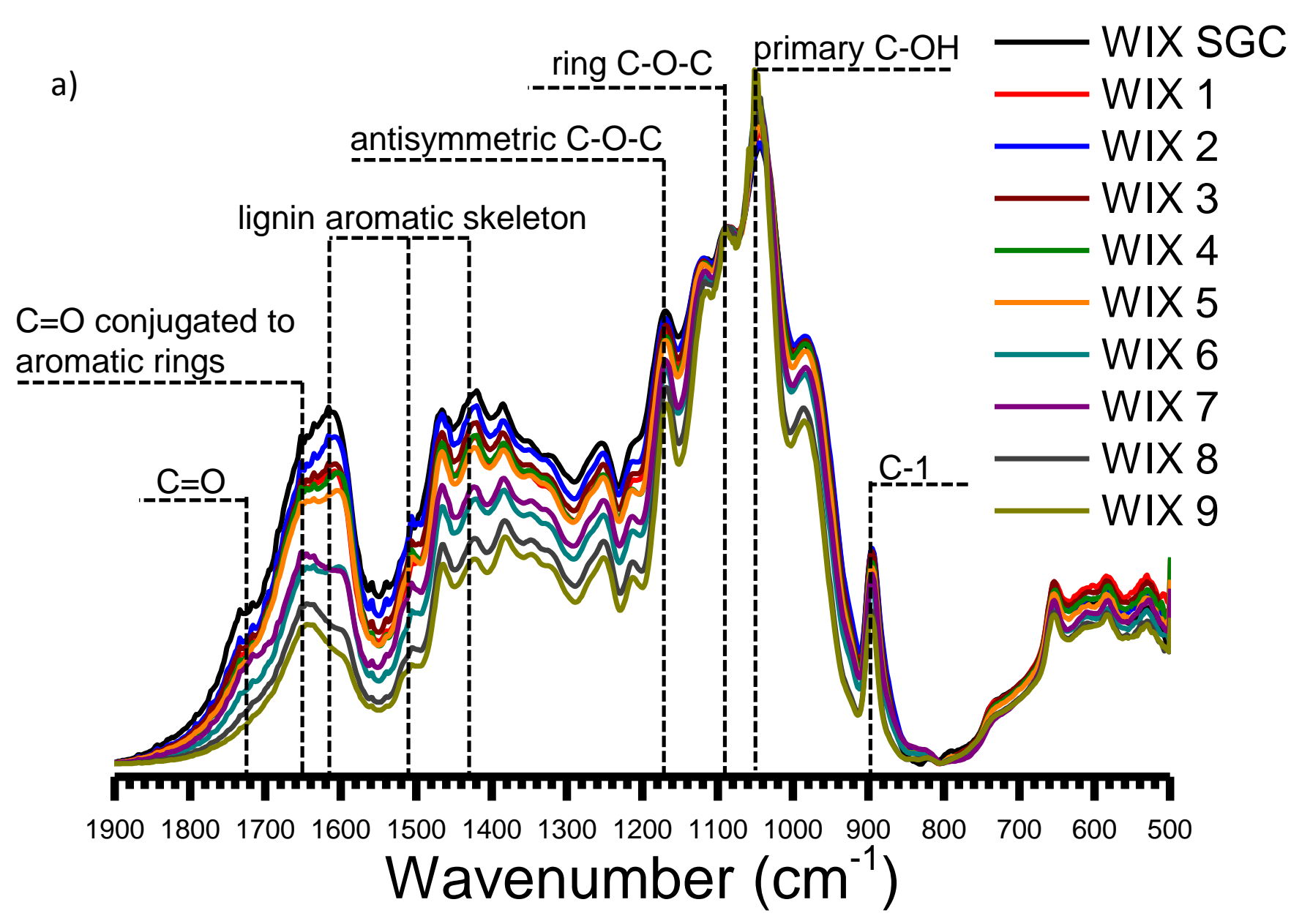




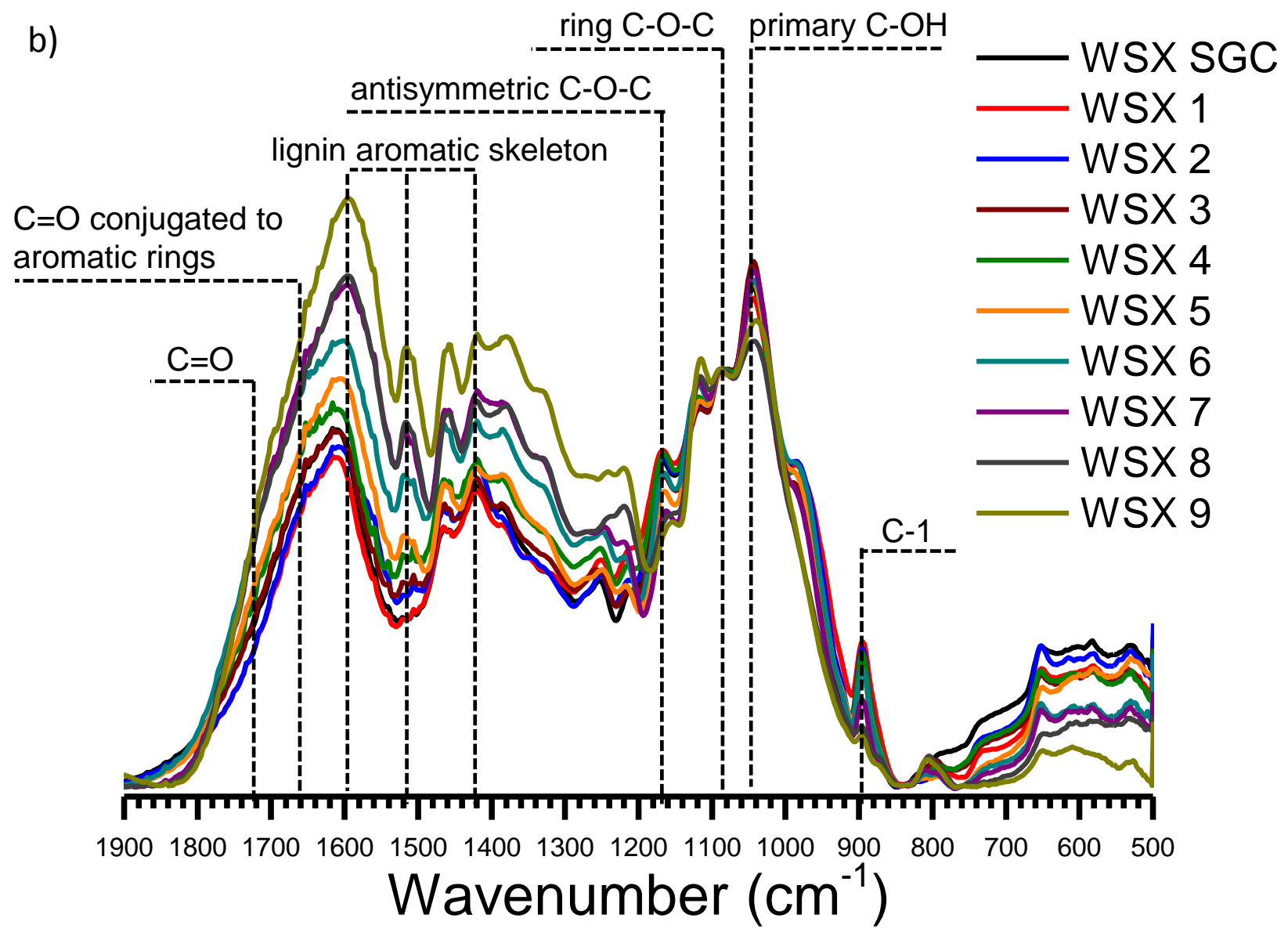

Fig. 7. Fingerprint region of crude water insoluble xylan (a) and water soluble xylan (b) as a function of GTP severity (spectra were normalized at the band around $1085 \mathrm{~cm}^{-1}$ ). Sample ID can be referenced to severity parameter in Table 3.

Resonance bands at $1620 \mathrm{~cm}^{-1}$ and $1510 \mathrm{~cm}^{-1}$ showed (Fig. 7b) characteristics associated with lignin (Chua \& Wayman, 1979) in the WSX samples. Although the lignin content for WSX was not quantified in this research due to the limited recovery yield, the normalized spectra of crude WSX exhibited higher absorbance intensity for WSX isolated from GTP fibers at high pretreatment severities relative to the xylan (Fig. 7b). These results indicated that more lignin moieties were associated with WSX as the GTP severity parameter increased. The decreasing intensity of resonance bands at $1161 \mathrm{~cm}^{-1}$ was indicative of the decreased glycosidic linkages in 
the crude WSX with increasing GTP severity, which is in good agreement with the lower absolute xylan content in WSX at high GTP severities.

The FT-IR spectral comparisons of WIX and WSX as a function of GTP pretreatment severity on the isolated crude xylan can be summarized as follows: for the WIX, more severe GTP processing resulted in the cleavage of glucuronic acid, suggesting a less substituted xylan backbone. WIX had more lignin contamination and less xylan was observed in the recovered crude WSX after GTP pretreatment compared to that in the WSX from non-pretreated fibers.

\subsection{Degree of polymerization of the recovered xylan in WIX (GPC Analysis)}

Due to the poor solubility of xylan in organic solvents, carbanilation was performed prior to GPC analysis to fully convert the hydroxyl groups for improved solubility and to limit aggregation. A typical reaction scheme used for xylan carbanilation in this work was shown in Fig. 2. The disappearance of hydroxyl groups in the xylan carbanilates was confirmed by FT-IR analysis (spectra can be found in Supporting Information Fig. S2). Absolute molecular weight results for xylan carbanilates as a function of GTP pretreatment severity are shown in Table 5.

Table 5 Absolute number average and weight average molecular weight of WIX carbanilates.

\begin{tabular}{llllll}
\hline Sample ID & $\log \left(R_{0}\right)$ & $M_{n}(\mathrm{KDa})$ & $M_{w}(\mathrm{KDa})$ & $\mathrm{DP}_{\mathrm{n}}{ }^{1}$ & $\mathrm{PDI}$ \\
\hline WIX SGC & - & 52.5 & 68.1 & 127 & 1.30 \\
WIX 1 & 3.55 & $45.8(6.2)$ & $51.1(6.9)$ & 123 & 1.11 \\
WIX 2 & 3.85 & $47.1(8.3)$ & $58.8(16.1)$ & 126 & 1.25 \\
WIX 3 & 4.02 & $46.2(7.9)$ & $52.1(9.2)$ & 124 & 1.13 \\
WIX 4 & 4.14 & $43.7(0.8)$ & $49.9(0.3)$ & 117 & 1.14 \\
WIX 5 & 4.44 & $47.3(9.4)$ & $55.0(11.2)$ & 127 & 1.16
\end{tabular}




$\begin{array}{llllll}\text { WIX 6 } & 4.61 & 42.0(3.6) & 48.0(3.0) & 113 & 1.14 \\ \text { WIX 7 } & 4.72 & 46.5(3.2) & 54.1(4.4) & 125 & 1.16 \\ \text { WIX 8 } & 5.03 & 45.8(2.4) & 54.8(0.3) & 123 & 1.20 \\ \text { WIX 9 } & 5.20 & 54.4(1.4) & 65.6(0.0) & 146 & 1.21\end{array}$

${ }^{1} \mathrm{DP}_{\mathrm{n}}$ : absolute number average degree of polymerization; $\mathrm{DP}_{\mathrm{n}}$ of WIX SGC is calculated based on 1 glucuronic acid/10 xylose ring and 1 rhamnose ring per each xylan chain; $\mathrm{DP}_{\mathrm{n}}$ of WIX isolated from GTP fibers is calculated based on no glucuronic acid and the known rhamnose amounts on xylan chain; lignin and other contamination is included in the $M W$ and DP calculation.

The extracted WIX displayed comparable molecular weight to the WIX isolated from nontreated fibers, resulting in a DP range of 110-150 (Table 5). No measurable xylan chain degradation occurred during GTP processing with increased severity. Although GTP pretreatment was conducted at similar, or even higher, severity conditions as prior steampretreatment studies, xylan was not hydrolyzed in the same way that occurs in steampretreatment where acetic acid release is responsible for severe xylan degradation. Instead, the molecular weight is preserved with xylan largely remaining in its polymeric form for the water insoluble sample. Additionally, the derivatized xylans showed a narrow molecular weight distribution, with the PDI in the range of 1.1-1.3 for all WIX samples isolated after GTP pretreatment. This narrow distribution most likely arose from the selective fractionation of the low molecular weight xylan in the water extraction steps. However, studies focused on alkali extraction of wood (LeBel \& Goring, 1963) and various pulps (Jacobs \& Dahlman, 2001) have also indicated xylan has a very low polydispersity.

\section{Discussion}

The current understanding of xylan molecular structure from wood was initiated by Timmel and co-workers more than 50 years ago that described xylan's acetylated structure and branched glucuronic acid groups (Croon \& Timell, 1960). Recent studies have further elucidated xylan's 
structure using modern analytical tools including the distribution of acetylated groups along the backbone (Busse - Wicher et al., 2014). While studies are beginning to probe the interactions of xylan with other cell wall components (Busse - Wicher et al., 2014), missing in the literature is a full discussion of the intermolecular association of xylan in the cell wall and why it is easily extracted without chemical modification, why there are portions that are less soluble, and the role of xylan's heterogeneity in plant functions.

For the level of extractability, if lignin is first removed, which was the last substance deposited on the polysaccharide framework of the cell wall, then almost all xylan is extracted from the polysaccharide network. Both accessibility and a changing xylan from a potential lignin-xylan network polymer to xylan would enhance solubility and extraction. Furthermore, swelling of the cell wall towards mercerization conditions, as well as deacetylation of the xylan backbone, further enhances xylan removal. For the non-processed wood fiber, WSX is clearly a crude mixture, predominantly composed of xylan, but also highly associated with lignin in significant quantities. Total water soluble xylan was over $5 \%$ of the untreated biomass, $15 \%$ of the accounted xylan in the wood, so this is a significant xylan portion that is fundamentally different in nature than the xylan portion extracted as WIX.

Based on the non-uniformity of xylan recovered from the cell wall and the careful processing methods that have been developed to limit disturbance to the structure, it is clear the plant cell wall requires xylan of a certain nature for structure and/or organizational purposes. Fractional precipitation of xylan from alkali using aqueous ethanol, as methanol crashes almost all xylan out of solution, provides some insight into the relationship between the degree of substitution with 4-O-methyl glucuronic acid and the molecular weight of the xylan (Dahlman, Jacobs \& Sjöberg, 2003). However, recent work on the biogenesis of xylan shows there may not be a 
straightforward relationship between size and substitution. Engineered mutants of Arabidopsis have shown that xylan substitution and backbone polymerization can be "uncoupled" in some cases (Mortimer et al., 2010). Furthermore, acetylation occurs after backbone substitution with glucuronic acid to the xylan, so there are multiple areas where the plant can synthesize structures with various substitutions that would be befitting to the needs of cell wall construction or physiological stresses (Chong et al., 2014). Therefore it appears that the complexity of xylan is of more fundamental nature, as branching and acetyl substitution are parameters that the developing plant can use to tune solubility during transport and adsorption onto the microfibrils (Mortimer et al., 2010). Just as the lignin component is known to vary in monomeric ratios within the cell wall, xylans are potentially modified befitting to their structural and organizational purposes. Hence, processing methods that create more uniform structures such as found with GTP will enable the recovery of a more uniform xylan component.

Although there are uniformity issues in the xylan streams, it appears there has not been a major technological roadblock in developing methods for xylan isolation, as a number of studies have looked into optimizing recovery from industrial sources. Furthermore, high extraction yields of xylan from kraft pulp can be achieved, although, some xylan is inaccessible at certain levels of alkali (Teleman, Larsson \& Iversen, 2001). This overall body of work on isolation and recovery suggests xylan could be an important by-product of the pulp and paper or wood industries, if there was a compelling economic reason to do so.

\section{Conclusions}

Glycerol thermal processing was used for enhanced biomass fractionation, exposing wood particles to temperatures up to $240{ }^{\circ} \mathrm{C}$. After GTP processing and water washing, $80 \%$ of the xylan was preserved in the pretreated biomass after water extraction. A sequential mild alkaline 
extraction was performed on the pretreated fibers for xylan fractionation to recover crude extracts in the form of a water soluble portion and a water insoluble portion. These two portions recovered in untreated biomass and to a lesser extent in the GTP biomass were significantly different in composition and structure. The xylan in the WIX was in polymeric form whereas that in the WSX had a much lower degree of polymerization based on end group analysis. More WIX was successfully recovered from the GTP pretreated fibers with increasing GTP severity, and the crude xylan had a maximum xylan purity of $84 \%$. Detailed FT-IR spectral comparisons indicated that severe GTP processing resulted in the removal of the relative glucuronic acid side-groups from the xylan backbone in WIX. Increased GTP severity resulted in less xylan being isolated in the WSX portion as it was pre-extracted during the water washing of the biomass. Molecular weight analysis confirmed the polymeric nature of the recovered WIX with an especially narrow molecular weight distribution. These results indicate that the isolated WIX after GTP pretreatment has lignin associated with it, however the material has a reduction in the amount of glucuronic acid side groups. These side groups usually limit crystallization and thus if the lignin can be removed through mild bleaching prior to xylan isolation, this could produce a highly attractive material for used in advanced renewable materials applications such as pharmaceutical drug delivery, hydrogels, advanced fibers, and barrier films.

\section{Supplementary data}

Supporting Information includes ${ }^{1} \mathrm{H}-\mathrm{NMR}$ and FT-IR spectra for derivatized WIX.

\section{Acknowledgements}


The authors greatly acknowledge financial support from USDA NIFA 2010-65504-20429 for the work along with support from the Institute for Critical Technology and Science of Virginia Tech and the Virginia Tech Graduate School. Additionally, this research was undertaken, in part, thanks to funding from the Canada Research Chairs Program in Advanced Renewable Materials and NSERC Discovery Grants Program for "Identifying Structural Motifs in Polysaccharides for Nanotechnology and Advanced Fibre Processing”.

\section{References}

Allen, E. W., \& Tollens, B. (1890). Wood-sugar (xylose) and wood-gum (xylan). Annalen(260), 289-306.

Brown, D. M., Goubet, F., Wong, V. W., Goodacre, R., Stephens, E., Dupree, P., \& Turner, S. R. (2007). Comparison of five xylan synthesis mutants reveals new insight into the mechanisms of xylan synthesis. The Plant Journal, 52(6), 1154-1168.

Busse - Wicher, M., Gomes, T. C., Tryfona, T., Nikolovski, N., Stott, K., Grantham, N. J., Bolam, D. N., Skaf, M. S., \& Dupree, P. (2014). The pattern of xylan acetylation suggests xylan may interact with cellulose microfibrils as a twofold helical screw in the secondary plant cell wall of Arabidopsis thaliana. The Plant Journal, 79(3), 492-506.

Chong, S.-L., Virkki, L., Maaheimo, H., Juvonen, M., Derba-Maceluch, M., Koutaniemi, S., Roach, M., Sundberg, B., Tuomainen, P., Mellerowicz, E. J., \& Tenkanen, M. (2014). O-Acetylation of glucuronoxylan in Arabidopsis thaliana wild type and its change in xylan biosynthesis mutants. Glycobiology, 24(6), 494-506.

Chua, M. G. S., \& Wayman, M. (1979). Characterization of autohydrolysis aspen (populus-tremuloides) lignins .3. infrared and ultraviolet studies of extracted autohydrolysis lignin. Canadian Journal of Chemistry-Revue Canadienne De Chimie, 57(19), 2603-2611. 
Croon, I., \& Timell, T. (1960). Distribution of substituents in a partially methylated 4-Omethylglucuronoxylan. Canadian journal of chemistry, 38(5), 720-723.

Dahlman, O., Jacobs, A., \& Sjöberg, J. (2003). Molecular properties of hemicelluloses located in the surface and inner layers of hardwood and softwood pulps. Cellulose, 10(4), 325-334.

Deutschmann, R., \& Dekker, R. F. (2012). From plant biomass to bio-based chemicals: latest developments in xylan research. Biotechnology Advances, 30(6), 1627-1640.

Evans, R., Wearne, R. H., \& Wallis, A. F. (1989). Molecular weight distribution of cellulose as its tricarbanilate by high performance size exclusion chromatography. Journal of applied polymer science, 37(12), 3291-3303.

Fengel, D., \& Wegener, G. (1983). Wood: chemistry, ultrastructure, reactions. Walter de Gruyter.

Gabrielii, I., Gatenholm, P., Glasser, W., Jain, R., \& Kenne, L. (2000). Separation, characterization and hydrogel-formation of hemicellulose from aspen wood. Carbohydrate Polymers, 43(4), 367-374.

Glasser, W. G., Kaar, W. E., Jain, R. K., \& Sealey, J. E. (2000). Isolation options for non-cellulosic heteropolysaccharides (HetPS). Cellulose, 7(3), 299-317.

Glasser, W. G., \& Wright, R. S. (1998). Steam-assisted biomass fractionation. II. Fractionation behavior of various biomass resources. Biomass and Bioenergy, 14(3), 219-235.

Glaudemans, C. P. J., \& Timell, T. E. (1958). The polysaccharides of white brich (betula papyrifera). IV. the constitution of the hemicellulose. Journal of the American Chemical Society, 80(5), 1209-1213.

Goring, D. A. I., \& Timell, T. E. (1960). Molecular properties of six 4-Omethylglucuronoxylans. The Journal of Physical Chemistry, 64(10), 1426-1430.

Gröndahl, M., Eriksson, L., \& Gatenholm, P. (2004). Material properties of plasticized hardwood xylans for potential application as oxygen barrier films. Biomacromolecules, 5(4), 1528-1535.

Hägglund, E., Lindberg, B., \& McPherson, J. (1956). Dimethylsulphoxide, a solvent for hemicelluloses. Acta Chem Scand, 10, 1160-1164. 
Hansen, N. M., \& Plackett, D. (2008). Sustainable films and coatings from hemicelluloses: a review. Biomacromolecules, 9(6), 1493-1505.

Hurlbert, J. C., \& Preston, J. F. (2001). Functional characterization of a novel xylanase from a corn strain of Erwinia chrysanthemi. Journal of bacteriology, 183(6), 2093-2100. Husemann, E. (1940). Wood polyoses: constitution. Journal fur Praktische Chemie, 155(ii), 13-64.

Jacobs, A., \& Dahlman, O. (2001). Characterization of the molar masses of hemicelluloses from wood and pulps employing size exclusion chromatography and matrix-assisted laser desorption ionization time-of-flight mass spectrometry. Biomacromolecules, 2(3), 894-905.

Johansson, M., \& Samuelson, O. (1977). Reducing end groups in brich xylan and their alkaline degradation. Wood Science and Technology, 11(4), 251-263.

Kacurakova, M., Capek, P., Sasinkova, V., Wellner, N., \& Ebringerova, A. (2000). FT-IR study of plant cell wall model compounds: pectic polysaccharides and hemicelluloses. Carbohydrate Polymers, 43(2), 195-203.

Kayserilioğlu, B. Ş., Bakir, U., Yilmaz, L., \& Akkaş, N. (2003). Use of xylan, an agricultural by-product, in wheat gluten based biodegradable films: mechanical, solubility and water vapor transfer rate properties. Bioresour Technol, 87(3), 239-246.

Koshijima, T., Timell, T. E., \& Zinbo, M. (1965). The number - average molecular weight of native hardwood xylans. Journal of Polymer Science Part C: Polymer Symposia (Vol. 11, pp. 265-279): Wiley Online Library.

Lambert, J. B., Shurvell, H. F., Lightner, D. A., \& Cooks, R. G. (1998). Organic structural spectroscopy. Prentice Hall Upper Saddle River, NJ.

LeBel, R., \& Goring, D. (1963). Solution properties of birch xylan. II. Fractionation and configuration. Journal of Polymer Science Part C: Polymer Symposia (Vol. 2, pp. 29-48): Wiley Online Library.

LeBel, R. G., Goring, D. A. I., \& Timell, T. E. (1963). Solution properties of birch xylan. I. Measurement of molecular weight. Journal of Polymer Science Part C: Polymer Symposia (Vol. 2, pp. 9-28): Wiley Online Library.

Maréchal, Y., \& Chanzy, H. (2000). The hydrogen bond network in I $\beta$ cellulose as observed by infrared spectrometry. Journal of molecular structure, 523(1), 183-196. 
Mian, A., \& Timell, T. (1960). Isolation and properties of a 4-O-methylglucuronoxylan from the inner bark of white birch (Betula papyri/era). Tappi, 43, 775-781.

Mortimer, J. C., Miles, G. P., Brown, D. M., Zhang, Z., Segura, M. P., Weimar, T., Yu, X., Seffen, K. A., Stephens, E., \& Turner, S. R. (2010). Absence of branches from xylan in Arabidopsis gux mutants reveals potential for simplification of lignocellulosic biomass. Proceedings of the National Academy of Sciences, 107(40), 17409-17414.

Overend, R. P., \& Chornet, E. (1987). Fractionation of lignocellulosics by steamaqueous pretreatments. Philosophical Transactions of the Royal Society aMathematical Physical and Engineering Sciences, 321(1561), 523-536.

Peña, M. J., Zhong, R., Zhou, G.-K., Richardson, E. A., O'Neill, M. A., Darvill, A. G., York, W. S., \& Ye, Z.-H. (2007). Arabidopsis irregular xylem8 and irregular xylem9: implications for the complexity of glucuronoxylan biosynthesis. The Plant Cell, 19(2), 549-563.

Peng, F., Peng, P., Xu, F., \& Sun, R.-C. (2012). Fractional purification and bioconversion of hemicelluloses. Biotechnology Advances, 30(4), 879-903.

Petzold-Welcke, K., Schwikal, K., Daus, S., \& Heinze, T. (2014). Xylan derivatives and their application potential-mini-review of own results. Carbohydrate Polymers, 100, 8088.

Sjöström, E. (1993). Wood chemistry: fundamentals and applications. San Diego, CA: Academic Press.

Sluiter, A., Hames, B., Ruiz, R., Scarlata, C., Sluiter, J., Templeton, D., \& Crocker, D. (2008). Determination of structural carbohydrates and lignin in biomass. Laboratory Analytical Procedure, 1-15.

Stoklosa, R. J., \& Hodge, D. B. (2012). Extraction, recovery, and characterization of hardwood and grass hemicelluloses for integration into biorefining processes. Industrial \& Engineering Chemistry Research, 51(34), 11045-11053.

Teleman, A., Larsson, P. T., \& Iversen, T. (2001). On the accessibility and structure of xylan in birch kraft pulp. Cellulose, 8(3), 209-215.

Timell, T. E. (1967). Recent progress in the chemistry of wood hemicelluloses. Wood Science and Technology, 1(1), 45-70. 
Torget, R., Walter, P., Himmel, M., \& Grohmann, K. (1991). Dilute-acid pretreatment of corn residues and short-rotation woody crops. Applied Biochemistry and Biotechnology, 28(1), 75-86.

Wise, L. E., Murphy, M., \& d'Addieco, A. A. (1946). Chlorite holocellulose, its fractionnation and bearing on summative wood analysis and on studies on the hemicelluloses. Paper Tr. J., 122(2), 35-43.

Zhang, W. (2015). Biopolymer structure analysis and saccharification of glycerol thermal processed biomass. (Vol. Doctor of Philosophy, p. 207): Virginia Polytechnic Institute and State University.

Zhang, W., Barone, J. R., \& Renneckar, S. (2015). Biomass Fractionation after Denaturing Cell Walls by Glycerol Thermal Processing. ACS Sustainable Chemistry \& Engineering, 3(3), 413-420.

Zhang, W., Sathitsuksanoh, N., Barone, J. R., \& Renneckar, S. (2016). Enhanced enzymatic saccharification of pretreated biomass using glycerol thermal processing (GTP). Bioresource technology, 199, 148-154.

Zhang, W., Sathitsuksanoh, N., Simmons, B., Frazier, C., Barone, J., \& Renneckar, S. (2016). Revealing the thermal sensitivity of lignin during glycerol thermal processing through structural analysis. RSC Advances. 